\title{
Development of integrated marine monitoring network on southern coastline of Caspian sea
}

\author{
A. Najafi-Jilani ${ }^{1}$ and A. Nik-Khah ${ }^{2}$ \\ ${ }^{1}$ Engineering, Islamic Azad University, Islamshahr Branch, Iran \\ ${ }^{2}$ Water Research Institute, Tehran, Iran
}

\begin{abstract}
Monitoring of water surfaces through permanent measurement of hydrodynamic and meteorological data is one of the main requirements in safe and sustainable water management. The Caspian Sea, the major surface water body in Iran, significantly affects more than $600 \mathrm{~km}$ of urban and industrial coastline. In the present work, an integrated marine monitoring network for the entire southern coastline of the Caspian Sea was developed. The main design concerns centered on the network measuring components and data recording, checking, filtering, gap recognition, and transferring systems. Four coastal monitoring stations were assigned, along with two regional collecting stations and one central data station for gathering, checking and delivering recorded data at different access levels. Applicable guidelines on selection of measuring devices for both shallow and deep water zones are presented herein.
\end{abstract}

KEY WORDS: Caspian Sea; Marine monitoring network; Hydrodynamics; Data measurement; Data checking

\section{INTRODUCTION}

Integrated marine monitoring networks are a necessity for coastal countries. They are designed and implemented principally for permanent measurement of seawater data including hydrodynamic and quality parameters. An integrated marine monitoring network consisting of four sensor-equipped buoys was first deployed on the North Amberland (UK) coast, specifically for continuous monitoring of seawater-level variation patterns, wave data including height and direction, and prediction of marine storms (Buchanan and Moore, 1986). The network was extended and improved by adding new measuring devices around the Irish coasts and developing data transferring systems for implementation between measuring stations (Walsh et al., 1995). Further, the number of coastal monitoring stations was increased, and the network was upgraded for special monitoring of seawater-quality parameters at industrial pollution sources and power plant cooling-system outfalls (MPMMG, 1998). An integrated marine monitoring network was also developed and implemented in Hawaii, specifically for prediction and measurements of tsunami generation and propagation, respectively (Petitt et al., 2002; Mulder and Arkle, 2003).

Corresponding author: A. Najafi-Jilani

e-mail:a.jilani@iiau.ac.ir
Codes and standard norms for development of marine monitoring networks and integration of international systems were issued by Favali and Beranzoli in 2006. Technical guidelines for the design of various components such as measuring devices, the location of monitoring buoys, and the data gathering intervals for each of the hydrodynamic and seawater-quality parameters also were introduced. These have been periodically updated based on the results of gathered data and have been applied for prediction of marine environmental conditions such as storms, violent waves and seawater-level variations (Kasahara et al., 2006; Davies et al., 2001; Vassallo et al., 2008). In Europe, marine monitoring design codes were developed in consideration of special seawater-quality criteria (Iannaccone et al., 2009; Jonge et al., 2006).

In this paper, a procedure for development of an integrated marine monitoring network in the southern waters of the Caspian Sea is presented. The network components, such as shallow and deep water measuring devices and coastal monitoring and central data stations, were designed specifically for the study area. The measuring components and data recording, checking, filtering, gap recognition, and transferring systems are designed. Four coastal monitoring stations were assigned, along with two regional collecting stations and one central data station for gathering, checking and delivering recorded data at different access levels. Applicable guidelines on selection of measuring devices for both shallow and deep water zones are presented herein. 


\section{COMPONENTS OF MARINE MONITORING NETWORK}

The main components of the marine monitoring network were designed based on the overall hydrodynamic patterns prevailing on the southern coastline of the Caspian Sea. The main measuring and monitoring parameters considered are listed in Table 1. The wave height, period and direction are measured with a directional wave meter, the seawater current with a current meter, the seawater level with pressure gauges, and the five seawater-quality parameters with appropriate instruments at five selected depths, respectively.

The measuring devices are located in both shallow and deep water areas within the four south-coastal regions of the Caspian Sea. The wave patterns in each region are determined based on the available wind data, including speed and direction. As an example, the wave-rose data in one of the regions, Anzali, on the southwestern coastline, are illustrated in Fig. 1. The basic wind data, in the form of windrose, are also illustrated. The wind data are converted to wave data by following the procedure recommended in the Coastal Engineering Manual (CEM, 2002). The wave data are calculated on the basis of a wind of 6-hour duration and of specific speed and direction, considering the modification factors for the land and sea states.

The data measured by the shallow and deep water devices are transferred to the adjacent coastal monitoring stations. Data gathering from the shallow water measuring device is carried out using a connecting cable. The necessary requirements for cable stabling on the sea floor are duly considered. Data transferring from onshore or deep water measuring buoys is accomplished with wireless radio systems. The measured data are collected at each of the coastal monitoring stations and, after preliminary checking, are transferred to the regional data center. The relationships among the monitoring network components are illustrated in Fig. 1.

Table 1 Main measuring parameters in marine monitoring network.

\begin{tabular}{|c|c|c|}
\hline No. & Measuring Parameter & Range \\
\hline \multicolumn{3}{|c|}{ a. Hydrodynamic Parameters } \\
\hline 1 & Wave Height & $0.2 \sim 20 m \pm 0.2 \%$ \\
\hline 2 & Seawater Current & $0 \sim 100 \mathrm{~cm} / \mathrm{s} \pm 0.1 \mathrm{~cm} / \mathrm{s}$ \\
\hline 3 & Seawater Level & $0 \sim 80 m \pm 0.2 \%$ \\
\hline \multicolumn{3}{|c|}{ b. Seawater-quality Parameters } \\
\hline 4 & Temperature & $1 \sim 30^{\circ} \pm 0.5^{\circ}$ \\
\hline 5 & Salinity & $1 \% \sim 25 \%$ \\
\hline 6 & $\mathrm{pH}$ & $6 \sim 10$ \\
\hline 7 & Turbidity & $0 \sim 5 \mathrm{NTU}$ \\
\hline 8 & Electrical Conductivity & $17000 \sim 35000 \mu \mathrm{m} / \mathrm{cm}$ \\
\hline
\end{tabular}
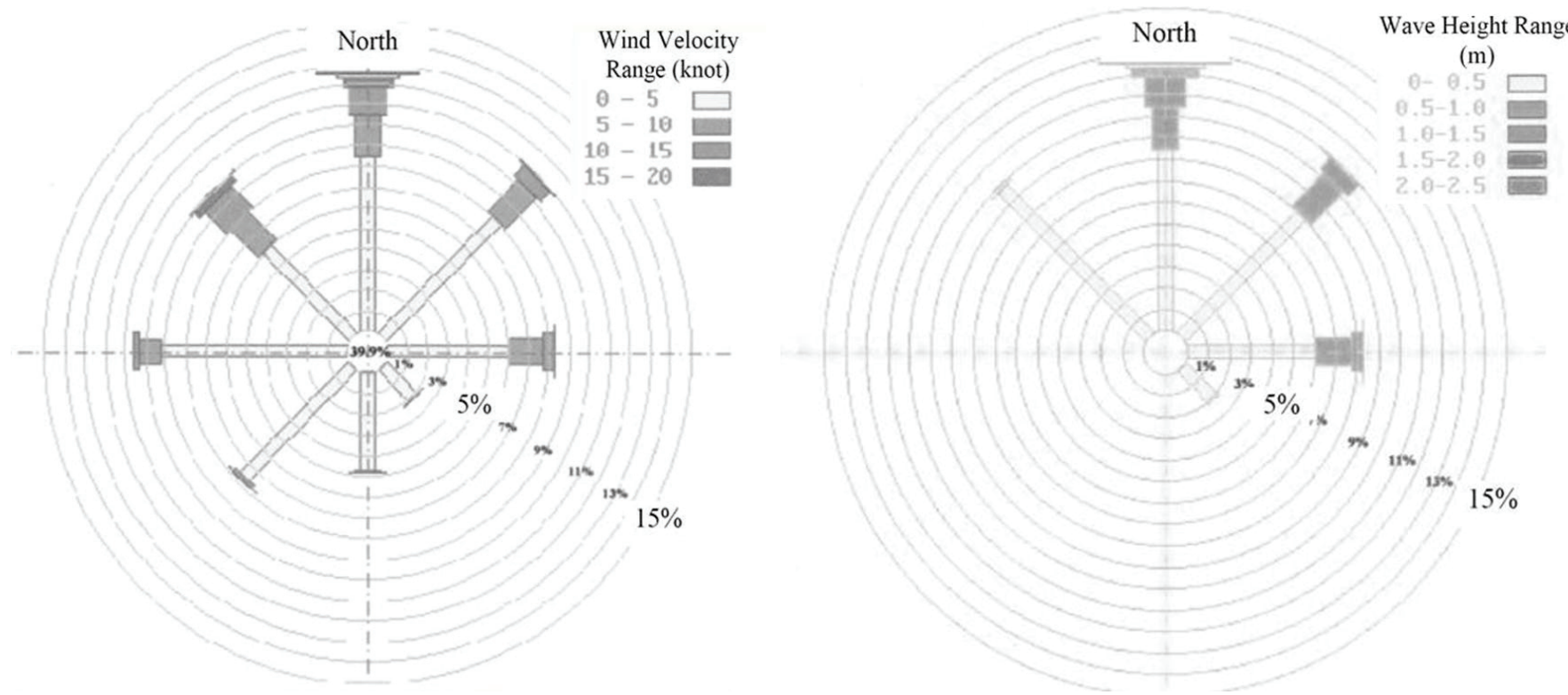

Fig. 1 Wind-rose (right) and wave-rose (left) at coastal monitoring station on southwestern coastline of Caspian Sea developed in this research. 
Four coastal monitoring stations are located at Neka, Noor, Anzali, and Astara, respectively, from east to west on the southern coastline of the Caspian Sea. At each coastal monitoring station (CMS), there is a deep water measuring system (DWS) and a shallow water measuring system (SWS).
The measured data are first collected at each CMS. After passing initial checks, the data are transferred from the two western CMSs to the western regional collecting station and from the two eastern CMSs to the eastern regional collecting station, as illustrated in Fig. 2.

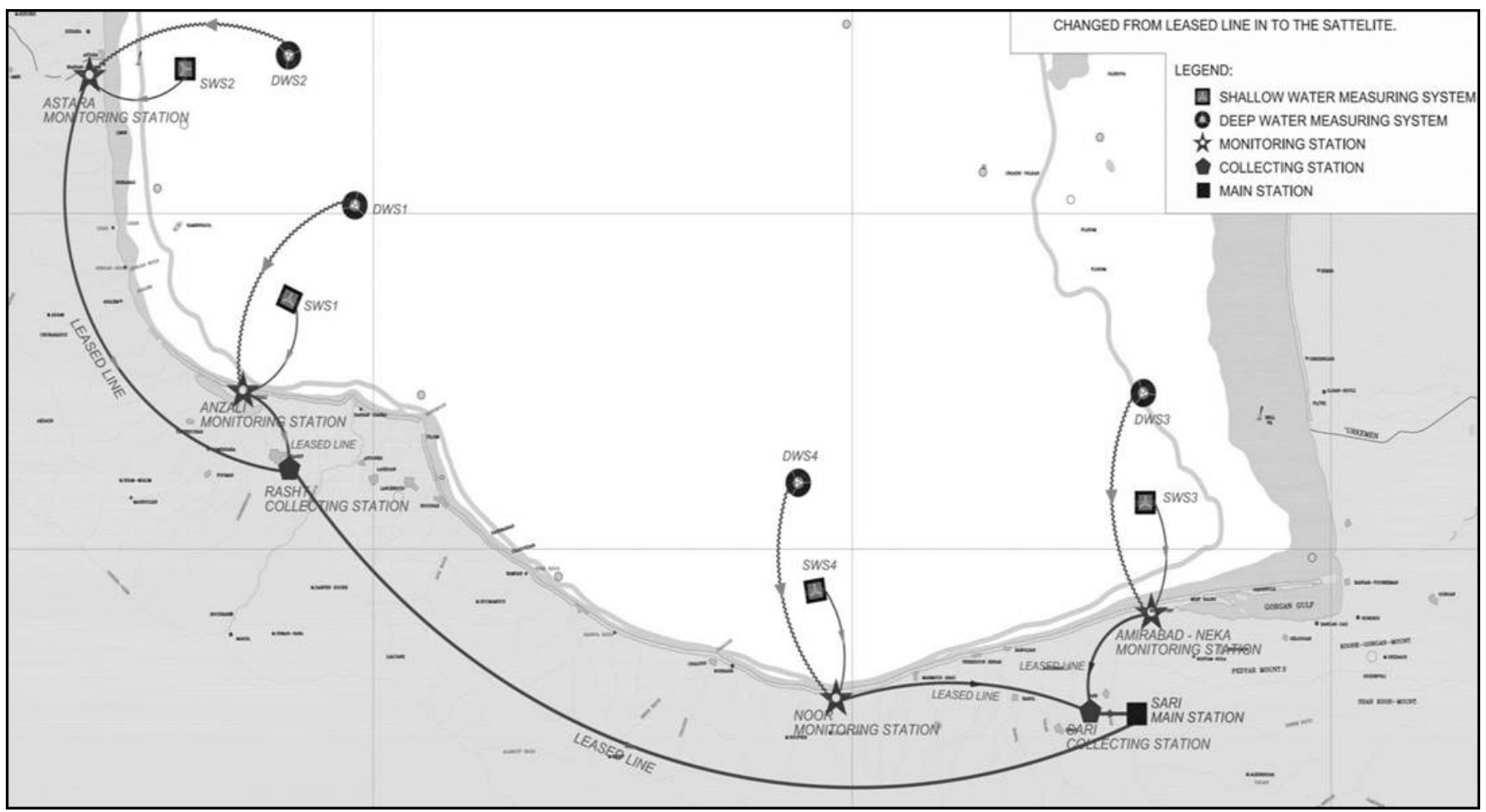

Fig. 2 Map of Integrated monitoring network on southern coastline of Caspian Sea.

A schematic diagram of the components of the integrated marine monitoring network on the southern coastline of the Caspian Sea is shown in Fig. 3.

As indicated, a meteorological system captures the weather conditions on the seacoasts, which are applied simultaneously with the oceanographic data. This is one of the strengths of the network system: the meteorological data can be applied as a reliable QC/double-checking criterion for the measured data. The scope of the technical operations pertaining in each of the main components of the network is apparent in the figure. The data transferring paths between the components also are shown.

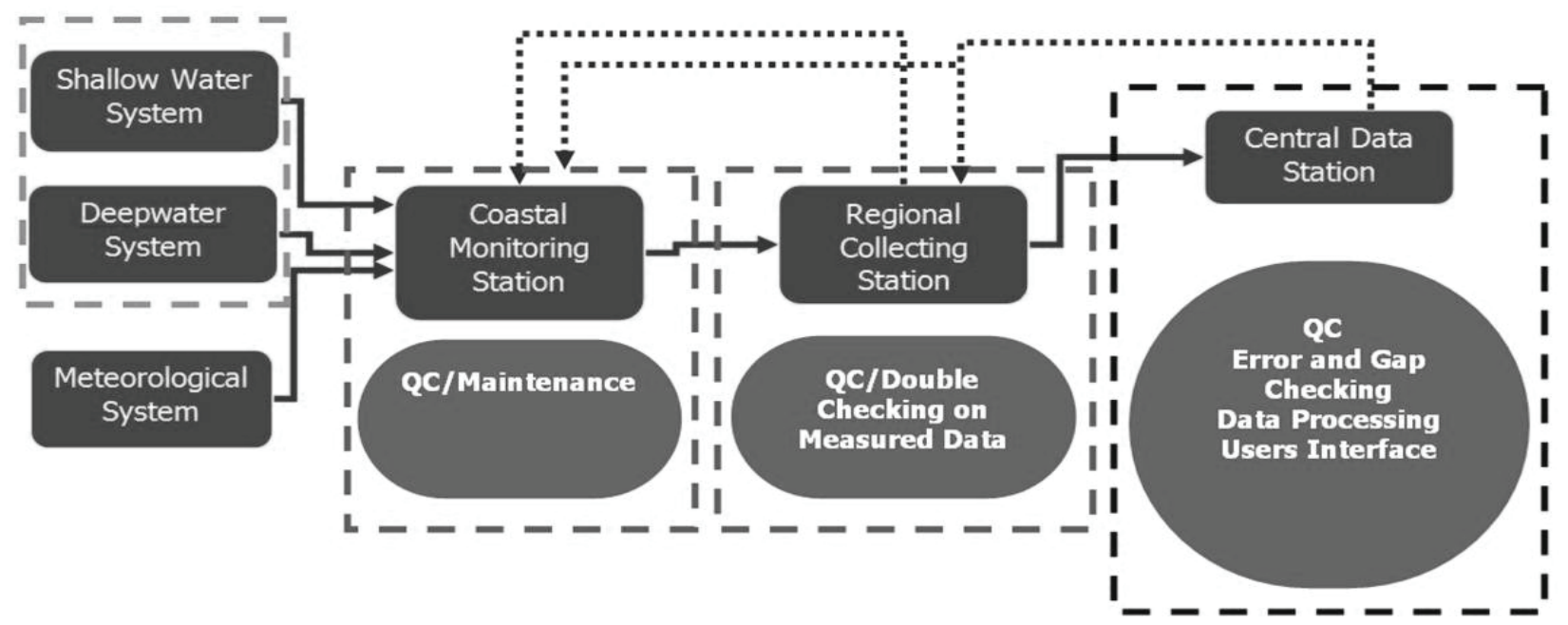

Fig. 3 Schematic diagram of components of integrated marine monitoring network on southern coastline of Caspian Sea. 
Data transferring from costal monitoring stations to regional collecting stations is accomplished by application of a web-based interconnection and a special leased line. Data transferring from regional collecting stations to the central data station is conducted in the same way.

Data transferring from costal monitoring stations to regional collecting stations is accomplished by application of a web-based interconnection and a special leased line. Data transferring from regional collecting stations to the central data station is conducted in the same way.

\section{MEASURING SYSTEMS IN SHALLOW AND DEEP WATER}

One of the main stages in network development is selection and optimization of appropriate measuring devices for the shallow and deep water zones at each of the four CMSs. The selection of sensors is carried out based on the measuring parameters, the data recording time interval, and the limitations of the sensors for data measuring and transferring. In the shallow water zones, a bed-installation system is utilized. In this system, the sensor, specifically a directional wave meter, can measure maximum $40 \mathrm{~m}$ wave heights (accuracy: $\pm 1 \mathrm{~cm}$ ) and wave directions within the full $360^{\circ}$ range (accuracy: $\pm 2^{\circ}$ ); wave periods within the $0.5 \sim$ 100 s range, meanwhile, can be captured by the directional wave meter's recording device (accuracy: 0.1s). A pressure transducer sensor measures the water pressure and, there from, the water surface variation. The maximum allowable water depth for the SWS is about $40 \mathrm{~m}$. The system's total weight is about $50 \mathrm{~kg}$. In the deep water zones, a measuring buoy is applied. Data transferring from the buoy to the adjacent CMS is achieved by VHF/UHF utilizing a satellite connection method. The wave height is measured within a $15 \sim 15 m$ range based on the still seawater level (accuracy: $\pm 10 \mathrm{~cm}$ ). The wave direction is captured within the full $360^{\circ}$ range (accuracy: $\pm 0.3^{\circ}$ ), and the wave period is measured within a $2 \sim 30$ s range (accuracy: $\pm 2 \%$ ). The total weight of the DWS is about $700 \mathrm{~kg}$. Fig. 4 shows both (shallow and deep water) measuring systems. As it can be seen in Figure (4) right, two configurations are applied for installation of deep water measuring device. These two forms are applied individually in each of four measuring stations.

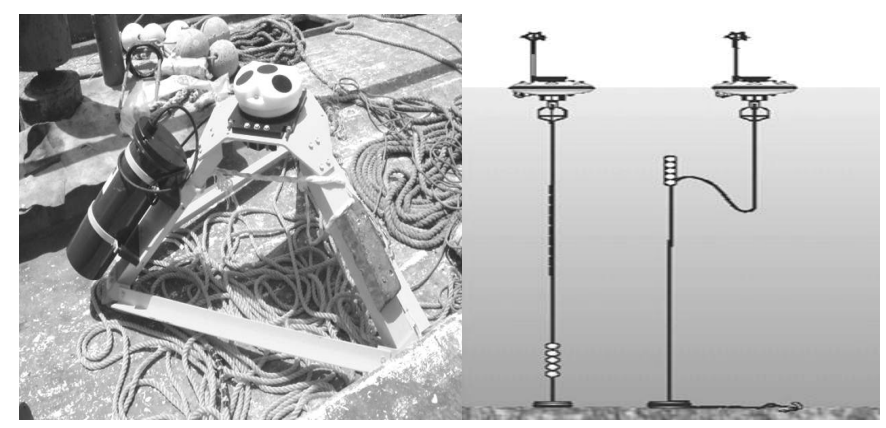

Fig. 4 Measuring systems in shallow water (left) and deep water zones (right).

\section{RESULTS AND DISCUSSION}

The marine monitoring network was implemented on the southern coastline of the Caspian Sea for permanent measurement of hydrodynamic and seawater-quality parameters in shallow and deep water zones. The measured data are controlled and checked to determine probable gaps or false sensor readings due to nonstandard measuring conditions. Quality control is applied to both raw and processed data. If the difference between the maximum and average data is more than six times the standard deviation, the recorded data are considered to be false, and interpolation cannot proceed. Additionally, the variation range between two adjacent recorded data is limited to the following value:

$\Delta G_{\max }=\left[\sigma \cdot S_{\max } \cdot \pi \cdot\left(\ln \left(\frac{T \sqrt{g S_{\max }}}{8 \sigma \pi}\right)\right]^{\frac{1}{2}} \cdot \Delta t\right.$

where, $\Delta \mathrm{Gmax}$ is the maximum allowable variation rate, $\mathrm{S}$ is the measuring parameter, $\sigma$ is the standard deviation, $\mathrm{T}$ is the recording duration, and $\Delta \mathrm{t}$ is the data recording time interval at the sensor. For processed data and especially for recorded wave data, quality control is carried out on the basis of the calculated significant wave height and period. That is, the calculated significant wave height $(H s)$ value in each recording period shall be positive and less than the maximum recorded wave height data; the maximum height shall not exceed $2.5 \mathrm{Hs}$; the up-zero crossing wave period (Tz) shall be in the $2 \sim 16 s$ range (it is continuously checked to ensure that it is more than the average and less than the wave period for the energy peak $(T p)$, which is about 3 $20 s$ ). Data checking for gap or missing data is carried out at all the four CMSs. At the regional collecting stations, quality control is performed on the raw data, and if the quality control criteria are satisfied, the data are processed and subjected to checking. Finally, the data are sent to the central data station and prepared for issuance to user organizations of the monitoring network.

\section{CONCLUSIONS}

An integrated marine monitoring network was designed for the southern coastline of the Caspian Sea. The main components of the network are as follows: four coastal monitoring stations each employing both shallow and deep water measuring devices; two regional collecting stations each responsible for two coastal monitoring stations and a central data station for gathering all recorded data and communicating with users. The sensors were selected in consideration of the special marine ecology requirements of the southern waters of the Caspian Sea. The bed-installation system with the necessary sensors was implemented as the shallow water measuring device. A suitable measuring buoy 
was selected for monitoring of hydrodynamic and seawaterquality parameters in deep water. Checking protocols for recorded data in both raw and processed forms were enforced for each of the components of the monitoring network. Applicable guidelines on selection of measuring devices for both shallow and deep water zones were presented herein.

\section{REFERENCES}

Buchanan, J. B. Moore, J. J., 1986. A Broad Review of Variability and Persistence in the Northumberland Benthic Fauna, Journal of the Marine Biological Association of the United Kingdom, Vol. 66, pp. 641657.

Coastal Engineering Manual (CEM)., 2002. USACE.

Davies, J. Baxter, J. Bradley, M. Connor, D. Khan, J. Murray, E. Sanderson, W. Turnbull, C. Vincent, M., 2001. Marine Monitoring Handbook, ISBN 185716550 0. pp. 405.

Favali, P. Beranzoli, L., 2006. Seafloor Observatory Science: A review., Annals of Geophysics, 49(2/3), pp.515-567.

Iannaccone, G. Guardato, S. Vassallo, M. Elia, L. Beranzoli, L., 2009. A new multidisciplinary marine monitoring system for the surveillance of volcanic and seismic areas, Journal of Seismological Research, 80(2), pp. 203-213.
Jonge, V. N. Elliott, M. Brauer, V. S., 2006. Marine monitoring: Its shortcomings and mismatch with the EU Water Framework Directive's objectives, Marine Pollution Bulletin, Vol. 53, Issues 1-4, pp.5-19.

Kasahara, J. Iwase, R. Nakatsuka, T. Nagaya, Y. Shirasaki, Y. Kawaguchi, K. Kojima, J., 2006. An experimental multidisciplinary observatory (VENUS) at the Ryukyu trench using the Guam-Okinawa geophysical submarine cable, Annals of Geophysics, Vol. 49 (2/3), pp.595-606.

Marine Pollution Monitoring Management Group, MPMMG., 1998. National Monitoring Programme: Survey of the Quality of UK Coastal Waters, Marine Pollution Monitoring Management Group, Aberdeen.

Mulder, M. Arkle, M. A., 2003. An improved system for quantitative sampling of benthos in shallow water using the flushing technique, Netherlands Journal of Sea Research, Vol. 14, pp.119-122.

Petitt, R. A. Wooding, F. B. Harris, D. Bailey, J. W. Hobart, E. Jolly, J. Chave, A. D. Duennebier, F. K. Butler, R., 2002. The Hawaii-2 Observatory, IEEE Journal of Oceanic Engineering, Vol. 27, pp.245-253.

Vassallo, M. Bobbio, A. Iannaccone, G., 2008. A comparison of seafloor and on-land seismic ambient noise in the Campi Flegrei Caldera Southern Italy, Bulletin of the Seismological Society of America, 98(2), pp.962-2974.

Walsh, P. M. Halley, D. J. Harris, M. P. Neyo, D. A. Sim, I. M. Tasker, M. L., 1995. Seabird monitoring handbook for Britain and Ireland, JNCC/RSPB/ITE/ Seabird Group, Peterborough, pp.259. 